\title{
Matijaner Meyera in Translation: Cultural Identity Construction Through Untranslatability of Language
}

Barnali Talukder*

Faculty of Arts \& Humanities University of Chittagong, Chattogram, Bangladesh

Corresponding Author: Barnali Talukder, E-mail: borno.talukder@gmail.com

\section{ARTICLE INFO}

Article history

Received: September 04, 2019

Accepted: November 04, 2019

Published: December 31, 2019

Volume: 10 Issue: 6

Advance access: December, 2019

Conflicts of interest: None

Funding: None

\author{
Key words: \\ Language, \\ Identity, \\ Translatability, \\ Untranslatability, \\ Bengli, \\ English, \\ Culture
}

\begin{abstract}
The concepts of language and cultural identity of a speaker are entwined as they complement each other. However, translation poses a challenge to the identity language predominantly constructs. Therefore, translatable elements of language get the stage of universality while the untranslatable-s essentially bring forth the culture they are descended from. In this study, a short story collection from Bangladesh, Matijaner Meyera, where there is a celebration of diverse branches of Bengali language, has been brought to light to show how untranslatability of a number of culture-oriented vocabularies vibrantly tells about Bengali culture. The primary resource includes a lot many culture-oriented vocabularies as well as few phrases that English, as a language, cannot accommodate in it. Inability of other languages to penetrate such culturerooted belongings of Bengali language showcases the power a language retains to protect itself from any invading force. This study has argued in favor of the untranslatable base of Bengali that English, due to cultural distance, cannot embrace linguistically. Therefore, such cultural difference eventually develops a distinct linguistic identity of Bengali through untranslatability that this study has attempted to divulge.
\end{abstract}

\section{INTRODUCTION}

Language may be held to represent various cultural traits, but our language is different; our language is transcendent---it is the language of God Himself. Language is an instrument of communication, but in our heart of hearts, we know God speaks only our language to us, because our language is us. (Ashcroft, 2014, p. 45)

The emphasis on the co-relation between us and language in aforementioned quote illustrates the inevitable relation language shares with culture regarding identity construction. Therefore, language no more remains a mere instrument of communication as it reflects 'the physical environment' under the influence of 'social factors' (Sapir, 1973, p. 90). Language itself, in consequence, gets changed into a mirror that tells a lot about physical, social and even national identity of a person. However, the debate over language's role in the development of a communal identity is a long-spanned one as it, for example, is even taken for granted that 'the lexicographic revolution in Europe', that Anderson proposes results in building 'a fraternity of equals' among its speakers and cements the conviction of considering language 'the personal property of quite specific groups' (Anderson,
2006, p. 84). The reflection, however, is accomplished with the help of certain linguistic elements such as vocabulary, syntax, structure etcetera. This particular aspect has repeatedly been mentioned in Edward Sapir who, to be specific, identifies vocabulary of language as one of the championing contributors to determine a speaker's 'social environment' (Sapir, 1973, p. 90). However, it is equally true that properties of language differ a lot depending on variables related to its source of origin. In accordance with this idea Deutscher Guy hypothetically pronounces in Through the Language Glass 'the grammar of some languages is simply not logical enough to express complex ideas' (2010, p. 1). As language inheres a good number of varieties, transforming it from one form to another is not an easy task that translation substantially endeavors to accomplish. However, it is debatable whether translation has any impact on such inherent spontaneity of language or not, as it has been referred in Language and Translation in Postcolonial Literatures 'nothing is really untranslatable - not everything can be translated' in the opinion of 'Princeton Scholar David Bellos' (Bertacco, 2014, p. 21). The way language determines a speaker's identity gets a dimensional change while undergoing a 
translation. Although translation is a widespread necessity and it is performed enormously across the world, translating a text from one language into another poses a threat to the originality as well as the discernibility of the source language the text is written in. In this study, therefore, how a short story collection Matijaner Meyera by Selina Hossain, derived from Bangladesh's soil, has encountered translatability problem due to the unavailability of certain vocabularies and phrases in English language has been brought to light. In doing so, it has been found how culture-specificity of words poses the difficulty of untranslatability and consequently contributes to develop a language-based cultural identity. Language, therefore, becomes a defensive medium that automatically retains the capability to resist any attack made by foreign language. To be more specific, it can be claimed that language reflects the social, cultural and communal identity of people through its properties such as vocabularies, structures. Therefore, such sociocultural elements of language deter external forces, that is, other languages, from domination instrumenting the power of untranslatability. In order to reflect on such linguistic impenetrable identity, the study here has attempted the translation of a Bangladesh's short story collection titled Matijaner Meyera.

\section{LITERATURE REVIEW}

Rajendran Shankaravelayuthan shows in an article titled "Untranslatability as a literary device" how Indian writers produce an artificially codified English language being deeply engrossed in Indian untranslatable milieu that results in a gap between textual world and real world (2017). In another context, it has been argued how Warnor \&Warnor translation of Rustam and Shorab has to face untranslatability problem due to their semantic methodology of translation and highly qualified style of Firdowsy employed in Shahanameh (Mashhady and Noura, 2012). However, how such difficulty of translation can be overcome and how different cultural terms categorically exist on the list of untranslatability, this has been revisited in "Translating culture: problems, strategies and practical realities" (Guerra, 2012). However, Selina Hossain who is claimed to be a writer who represents the voice of the commoners, mainly the female ones, experiments different colloquial-s of Bengali. Therefore, an abundance of culture-specific words can be found in her writing that substantially support how language retains an identity power. This particular aspect, that is, cultural identity construction through language, has yet not been in the light so prominently that this study has focused on.

\section{Language and Identity}

A good number of linguists have reflected on the identity construction perpetuated by language. Language along with serving the purpose of communication turns into a mirror that reflects a speaker's social, cultural as well as geographical circumstances that, however, is not detached from a number of variables contributing to the formation of distinct structures of different languages. However, construing terms and structure of language also largely relies on a speaker's socio-cultural conditions. To quote Valentin Nikolaevich Voloshinov, in this regard, is relevant who believes 'the production of meaning is social rather than an individual phenomenon' (“Theorising the sign", 2000, p. 16) by which assertion it can easily be realized that linguistic meaning is integrated in the speaker's social upbringing. Depending on above functionality of language, it can be declared that language satisfies a two-face purpose - language contributes to shape a speaker's identity and is itself shaped simultaneously under the influence of a speaker's social and cultural circumstances. Edward Sapir and his student Benjamin Lee Whorf propose a groundbreaking idea that believes in the determining role of the mother tongue to think and to perceive the world (Deutscher, 2010, p. 130). Therefore, SapirWhorf hypothesis connects language to a mechanism that forms perception that in the language of Benjameen Lee Whorf gets much vivid representation, 'the structure of the language one habitually uses influences the manner in which one understands his environment. The picture of the universe shifts from tongue to tongue' (Stuart, 1956: vi). In consequences, according to Whorf's hypothesis, it is language that determines how one envisions the universe. Diarmait Mac Giolla Chriost, in one of the articles titled "Globalization and Transformation: Language Planning in New Contexts", proposes, 'language is an ever-changing artefact that is both shaped by and helps shape social life, sometimes contributing to, sometimes undercutting, constructions of identity and otherness' (2007, p. 36). This definition is of particular interest in this study because here language conditions as well as is conditioned based on a speaker's socio-cultural orientation. Glancing at all these propositions regarding language, it is not difficult to understand that each language authentically develops a distinct identity that consequently contributes to build distinct identities of the speakers belonging to different socio-cultural circumstances. This idea can more be reinforced with a quote, 'This means that the ways of making sense of the world which we take from our language will be distinct depending on which language we learn' ("Language and Subjectivity", 2000, p. 101). Depending on all these references stated above, it can, therefore, be deducted that to a number of linguists, language plays a determining role in identity construction of its speakers. Language retains this identity in it as well that, on scrutiny, much boldly can reflect a communal identity.

\section{Language and Translation}

'For 2500' years 'the view has persisted' that 'a line of thought expressed in any language could be translated without loss of meaning into another language' (Stuart, 1956, p. Vii). However, the task of translation is not such linear one as it undertakes the responsibility of translating an entire culture into another one. To give more importance to this matter, it can be said that translating a language is not confined to mere 'techniques' or 'skills'; instead it has turned into an important aspect of any 'culture' (Bertacco, 2014, p. 20). As language has a distinguished connection to a speaker's culture and identity, translating it becomes a challenge to keep those concerns alive and unaffected. However, this challenge 
is not frightening, rather endeavoring as Michael Cronin believes:

All translators are cultural cosmopolitans, in that going to the other text, the other language, the other culture, involves that initial journey away from the location of one's birth, language, upbringing. (Cronin, 2006)

On top of that, Homi K. Bhaba believes that all languages have a 'Third space of enunciation' regardless of their 'provisionality' and 'untranslatability’ (Ashcroft, 2014, p. 49). Consequentially, it can be argued that translation furthers the chance of divulging new truths about language. On the other hand, translation can be really challenging as in the language of Benjamin, illustrated in a context of poetic translation, 'translators are doomed to be unfaithful to the poet, because language itself is "unfaithful" (Ashcroft, 2014, p. 49-50). In consequence, it can be discerned that translation always looks for a middle way to correspond between the untranslatability and the translatability. Translatability, in this regard, reveals a cosmopolitan character of language that can make space for other cultures. On the other hand, untranslatability of language further establishes the distinctness languages unconsciously reserve in them. Therefore, untranslatability turns out to be the room where cultural identity demonstrates its strength.

\section{Translating Matijaner Meyera}

Matijaner Meyera is a collection of short stories written in Bengali and published in 2012. About the stories in an article titled "Postcolonialism, Feminism and Stories of Selina Hossain" (in translation) Masudujjaman reviews that the stories of Selina Hossain stand synonymous with the stories of women - the holistic stories of Bangladesh's women that essentially interact with diverse shades of woman life - from grassroot woman to elitist ones, from lower caste to higher caste, from common, naïve woman to politically conscious ones (author's translation) (2002). This particular review is of immense significance as versatility of Hossain's storytelling uncompromisingly includes a multilateral use of language to orient fiction with reality more vividly. It, consequently, complicates the task of translation that in an interview with Rifat Munim, Syed Manzoorul Islam clarifies and briefs about the difficulties of translation from Bengali to English:

Translating from Bengali to English is a tricky business, not only because the social realities the two languages represent are ever so different but also because the complex range of cultural references and their accompanying signifying practices are very difficult to transfer from one language to the other.

Therefore, the stories of Hossain, it has been observed while translating, compile a number of words that cannot comply with the English language sentiment. To be more precise, English fails to accommodate words from Bengali that are deeply entwined with cultural stimuli of the nation. At the same time, some examples have also been found where language expresses different dimensions of culture. Translation, therefore, complicates the capability to make meaning of such expressions without immediate interpretation. Based on these two most fundamental articulations of language the paper has tried to develop two perceptive ideas that culminate in a single denouement - language becomes a manifesting way of cultural identity.

\section{Culture-rooted Vocabularies in Matijaner Meyera}

It is indisputable that translation plays a big role in universalizing any national or regional production, but the cultural orientation that language necessarily shares with geographical and political milieu of any particular country cannot easily be translated. To reflect more clearly on this particular language aspect, this study has divided a list of sampling words into two categories - concrete and abstract. On the list of concrete words, the most distinguishable ones have been stated below with meanings referred from Bangla Academy Bengali-English Dictionary. Benarasi is a much popular one on the repertoire of Sari which is not necessarily originated from Bangladesh, but a Bengali favorite and in Bangla Academy Bengali-English Dictionary which has been interpreted as 'made in Benaras made of Benaras silk (582).' Resembling this popular dress mentioned above, alpona is another artistic endeavor of Bengal that means, according to Dictionary, 'auspicious white paint on the floor, walls etcetera with liquid pigment of rice powder according to indigenous tradition (60).' Deviating from this creative aspect of Bengal, a number of physical objects have also been put together which are closely related to Bengali lifestyle, for example, the word gouale has been referred, in Bangla Academy Bengali-English Dictionary, as 'a cow-shed (175).' Another such word is machan which is used in Bangladesh's villages to grow vegetables and in the abovementioned dictionary which has been claimed to be 'platform, dais, stage, shelf, scaffold (655).' To go to next one, khupri can be a good example as it has been translated into English as 'a small house; a hovel; a shack (156)' in Bangla Academy Bengali-English Dictionary. Another such exemplary stand is gamcha that the dictionary has construed in English as 'a napkin made by handloom (167).' With the same instance comes another word ghomta that Bangla Academy Bengali-English Dictionary translates as 'a cover for woman's head and forehead with the end of sari; a veil (184).' Much related to the word ghomta is anchol that the same dictionary tries to translate into English as 'the loose end of a woman's sari (43).' Dhekighor which is an everyday necessity for any agriculture-based family has been interpreted in dictionary as 'the shed in which a husking pedal is fixed (258).' While translating Matijaner Meyera, a lot many of such words have come across among which the above ones represent much distinctly the culture-rooted articulation of language. Even there are few words of which the interpretive English equivalent have not been found in dictionary: sanki, chika, chunkali etcetera. In the next section, the study has taken into account a few abstract words that, to be specific, are associated with human emotions. The first one, in this regard, has been selected as oviman that has been translated into English as 'offended state of mind, pique, sensitiveness, mental perturbation (35)' in Bangla Academy Bengali-English Dictionary. The following one, on this list, is sangsar that, in English translation, becomes 'the world; 
secular life; worldly life; mundane existence, domestic life; family, earthly attachment and interests; marriage, housekeeping, household; married couple (775), according to the same dictionary referred above.

\section{An Analytical Look at Vocabularies in Matijaner Meyera}

While translating into English, the words above have been inserted unchanged as there is no direct English equivalent of these words. Therefore, the way these words have elaborately been translated into English cannot grab the essence of the significances as even the concrete words retain a contextual purpose that only the culturally symmetrical readers can understand. For instance, the word Benarasi, in Matijaner Meyera, has appeared in the story "Mukh" that no more remains a mere name of a Bengali dress, but becomes a symbol of a girl's desire, dream and future as Bengali girls traditionally wear it on their wedding. In the story a character named Alimon wears it to begin a new phase of life which the single word Benarasi can much enormously illustrate (Hossain, 2012, p. 78). Therefore, Benarasi turns into a symbolic company in their journey to a new life. Similarly, the word alpona refers to a traditional art form that originally Bengali people make during any traditional occasion. Hossain uses this word in the story "Lipikar Biye and Otoppor" where the female character Lipika is going to be married off and that is why alpona is being created to signify festivity (Hossain, 2012, p. 87). This ongoing discussion necessarily includes words such as ghomta and anchol; consecutively these words bring to context the feminine representation in Bangladesh. In a story titled "Baidhobbo" Achia, a rural female, appears in front of her father without ghomta (Hossain, 2012, p. 43) and consequently reveals a haphazard state of her mind as Bengali woman comes in ghomta mainly to avoid male gaze as well as to show respect. Anchol, in this regard, has been mentioned in a story titled "Hridoy o Sromer Sangsar" where Matibanu, a minor character, uses anchol to hide her tears. (Hossain, 2012, p. 47) Therefore, instead of being only an extended part of a sari, an anchol can be used for multipurpose that a Bengali culture-oriented mind can understand.

Along with such concrete objects directly related to culture, the significance of abstract words that are deeply embedded in cultural orientation is of much importance. The first story "Matijaner Meyera" depicts the life-change of Matijan who, after marriage, instead of being welcomed, becomes a victim of torture and negligence. To her, the definition of sangsar is a new world where a girl slowly becomes a woman through an odyssey of good as well as bad experience and authoritative existence (Hossain, 2012, p. 9). Therefore, the English words that stand for the word Sangsar cannot adequately detail the emotional and phenomenal significance of it. In the same story Matijan mentions the word oviman in delineating her emotion toward her father (Hossain, 2012, p. 11). As her father arranges hastily her marriage which is considered to be the ultimate destination of a girl's life, she feels an anger, but it is bereft of revenge, abuse or attack, instead it is concomitant with a feeling of inexpressible sorrowful anger. This word, again, fails to be properly translated into English as it is closely connected to an emotion erupted from Bengali soil.

\section{Different Route, Single Destination}

Besides all these particularities that words represent about a language, language also applies lots of turns and twists to mean something linear. Translating these turns and twists can be challenging as these are so deeply ingrained in culture. At the same time, direct translations of those can diminish the charm of original language-based construction of them. In translating Matijaner Meyera, this particular aspect has remarkably been visible. In the story "Matijaner Meyera" her mother-in-law steps forward to chase Matijan away as she fails to give birth to a baby boy. To refer to the word boy, her mother-in-law, Gulnur, uses the phrase, 'I need a light to my lineage' (author's translation) (Hossain, 2012, p. 18). The comparison between boy and light of the family is an indirect way to reflect the socio-cultural state of a country. The phrase also tells a lot how masculinity, in Bangladesh, is valued more than femininity and certainly results in the formation of patriarchal as well as female-subjugated society. To an English reader, comparison between light and boy can be pondering as English culture might not be familiar with such socio-cultural condition. In another story "Akalir Station Jibon," in the course of the story, an aunt of Akali violently asks her, 'what destruction have you done to yourself? What will happen now?' (author's translation) (Hossain, 2012, p. 23). In the story Akali gets pregnant due to an extra-marital relationship with her master's son. Therefore, her aunt refers to pregnancy as a destruction, in Bengali sarbonash. Use of this word clearly depicts how a Bangladeshi society sees extra-marital relationship - no doubt, it is considered here to be a shameful act - being in any such relationship is utterly disgraceful for a girl in this society. At the same time the Bengali word Sarbonash has been used to mean loss of virginity. Therefore, the use of language here gets closely connected to the way one sees a fact in different frame.

\section{DISCUSSION}

At the beginning of the study, it has theoretically been brought to light how language is one of the determining factors in revealing a speaker's identity. Examples collected from Selina Hossain's short story collection, Matijaner Meyera, strongly support this idea once more. The concrete and abstract words are so closely connected to Bangladesh's culture that the appropriate as well as contextual equivalent English words are not present in Bengali-English dictionary. Such untranslatability of these words reinforces the idea that identity formed within the frame of language cannot so easily be transformed into another. Identity that has been created through Bengali in the analysis above cannot wholly be grasped in English. To be clearer, the concrete words, listed for this study, are deeply influenced by Bengali culture and society - for instance, might it be anchol or ghomta, each of the words sheds light on the state of Bengali female community who belongs mainly to patriarch conservative society. Similarly, words like alpona and Benarasi are so immensely ingrained in Bengali soci- 
ety and culture that utterance of any of these words brings a flavor of festival to every Bengali-oriented mind. For further analysis, the phrasal articulations some of which have been included in above discussion, primarily relate to Bengali culture as connecting male-child to light of a house undoubtedly declares how valuably man is nurtured in this society. Bengali as a language here retains the pride that her inherent properties cannot be invaded by any foreign language only on want. On the other hand, English as a language fails to accommodate those words that are inseparably rooted in Bangladesh's soil. However, such distinct identity of individual languages is not always plainly stated, rather language implements lots of techniques to reach a single meaning; that is where identity of a speaker's culture gets a vivid reflection.

\section{CONCLUSION}

Language has been a medium of communication and instruction from the beginning of civilization. Translation, therefore, has been imperative to establish an intercommunication across the world. Despite an unconditional acceptance of translation worldwide in order to transfer knowledge and information from one corner to another, culture retains certain particles that disagree to succumb to the limit of translatability. In consequence, the scope of untranslatability is what creates space for the reflection of cultural individuality. Selina Hossain's Matijaner Meyera is an explorative collection that deals with different women branching from different walks of life. Their language resultantly varies distinguishably from rustic to sophisticated articulations. This short story collection, therefore, provides the chance to experiment how translating into English fails to accommodate all words a big amount of which are deeply rooted in Bengali culture. Consequently, even in English translation, the stories emanating from Hossain's collection essentially reflect Bengali culture that is what is claimed to be the untranslatability of culture. Therefore, such untranslatability empowers a language as well as culture to escape any intellectual invasion.

\section{REFERENCES}

Anderson, B. (2006). Official Nationalism and Imperialism. Imagined Communities, (pp. 83-111). Verso: London, New York.

Ashcroft, B. (2014). Bridging the Silence/ Inner Translation and the Metonymic Gap. In Simona Bertacco (Ed.), Language and Translation in Postcolonial Literatures, (pp. 43-70). New York, Routledge.

Ashcroft, B. (2014). Bridging the Silence/ Inner Translation and the Metonymic Gap. In Simona Bertacco (Ed.), Language and Translation in Postcolonial Literatures, (pp. 43-70). New York: Routledge.

Bertacco, S. (2014). Introduction/ The Fact of Translation in Postcolonial Literatures. In Simona Bertacco (Ed.), Language and Translation in Postcolonial Literatures, (pp. 18-41). New York: Routledge.

Chase, S. (1956). Forward. In John B. Carroll (Ed.), Language, Thought and Reality, (pp. v-x). Massachusetts: The M. I. T. Press.
Chriost, D M G. (2007). Globalisation and Transformation: Language Planning in New Contexts. In Máiréad Nic Craith (Ed.), Language, Power and Identity Politics, (pp. 21-42). New York: PALGRAVE MACMILLAN.

Cronin, M. (2006). Translation and the new cosmopolitanism. Translation and Identity, (pp. 6-42). Oxon: Routledge.

Deutscher, G. (2010). Prologue. Through the Language Glass, (pp. 1-22). New York: Metropolitan Books.

Deutscher, G. (2010). Crying Whorf. Through the Language Glass, (pp. 129-156). New York: Metropolitan Books.

Guerra, A. F. (2012). Translating culture: problems, strategies and practical realities. Art and Subversion, 1(3).LT.1. [sic] - a journal of literature, culture and literary translation. doi: 10.15291/sic/1.3.1t.1

Hossain, S. (2012). Matijaner Meyera. Godyopodyo: Dhaka. In Lucy Burke, Tony Crowley \& Alan Girvin (Eds.). (2000). Theorising the Sign. The Routledge Language and Cultural Theory Reader. (pp. 13-20). London, New York: Routledge.

In Lucy Burke, Tony Crowley \& Alan Girvin (Eds.). (2000). Language and Subjectivity. The Routledge Language and Cultural Theory Reader, (pp. 100-104). London, New York: Routledge.

In Mohammad Ali, Mohammad Moniruzzaman \& Jahangir Tareque (Eds.). (1994). Bangla Academy Bengali-English Dictionary. Bangla Academy Press: Dhaka.

Mashhady, H \& Noura, M. (2012). A Case Study: Translation Problems in the Story of Rustam and Sohrab Based on Warner \& Warner Translation. English Language Teaching, 5(2). doi:10.5539/elt.v5n9p115, URL: http:// dx.doi.org/10.5539/elt.v5n9p115.

Masuduzzaman. (2002). Uttor Uponibeshbad, naribad o Selina hossainer golpo. Retrieved from https://www. kaliokalam.com/\%E0\%A6\%89\%E0\%A6\%A4\%E0$\%$ A7\%8D $\%$ E0\%A6\%A4\%E0\%A6\%B0-\%E0\%A6\%89 $\%$ Е $\%$ А $6 \%$ AA $\%$ Е $\%$ A6\%A $8 \%$ Е0\%A6\%BF\%Е0\%A $6 \% \mathrm{AC} \% \mathrm{E} 0 \% \mathrm{~A} 7 \% 87 \% \mathrm{E} 0 \% \mathrm{~A} 6 \% \mathrm{~B} 6 \% \mathrm{E} 0 \% \mathrm{~A} 6 \% \mathrm{AC} \% \mathrm{E}$ 0\%A6\%BE\%Е0\%A6\%A6-\%Е0\%A6\%A $8 \%$ E0\%A6\% BE $\%$ E0\%A6\%B0\%Е0\%A7\%80\%Е0\%A6\%AC\%Е0\% $\mathrm{A} 6 \% \mathrm{BE} /$

Sankaravelayuthan, R. (2017). Untranslatability as a literary device. Retrieved from https://www.researchgate.net/ publication/321161481_Untranslatability_as_a_literary_device

Sapir, E. (1973). Language and Environment. In David G. Mandelbaum (Ed.), Selected Writings of Edward Sapir in Language, Culture and Personality, (pp. 89-103). London: University of California Press.

The Author as Self-Translator:AConversation with Syed Manzoorul Islam. Rifat Munim and Syed Manzoorul Islam. (2014). World Literature Today, 88(3-4), 66-68. DOI: 10.7588/ worllitetoda.88.3-4.0066. Retrieved from https://www. jstor.org/stable/10.7588/worllitetoda.88.3-4.0066 . https:// www.jstor.org/stable/10.7588/worllitetoda.88.3-4.0066?se$\mathrm{q}=1$ \#page_scan_tab_contents 